\title{
DECONSTRUCTING MASCULINITY: CHANGING PORTRAYAL OF INDIAN MEN ON OTT PLATFORMS
}

\author{
Seema Sangra \\ Assistant Professor-Amity University, Dubai Campus
}

\begin{abstract}
Over the years, media has been invoking 'hegemonic masculinity' and producing a one-tone representation of men, who are linear, flat, and in line with the traditional definition of manliness. Such unrealistic images of men lead to the reinforcement of prejudice against other genders, which also has damaging repercussions on men. However, there is a noticeable silver lining with the entry of Over the Top (OTT) platforms as they are challenging such representations. These platforms chart out the basic premise of the theory of social construction of reality that helps construct new realities of masculinity, defying 'hegemonic masculinity.' This paper aims to critically examine and evaluate masculinity's representation in various Indian OTT platforms' content and understand how the Indian OTT content is blurring masculinity images instead of what the cultural products are portraying. The paper also intends to analyse the male lead characters and their positioning, which does not compartmentalise men's attributes into the existing patriarchal male image, representing them as real and relatable. This paper substantiates the method of discourse analysis. Three content from Indian OTT platforms are selected with the purposive sampling method - 'Little Things' Season 1 \& 2 on Netflix, 'Made in Heaven' on Amazon Prime Video, and 'Yeh Meri Family' on TVF Play, to analyse along variables formulated to justify the hypothesis - 'Indian content on OTT platforms is blurring the one-tone representation of masculinity'. The paper proposes a revised study of men and masculinity, challenging the patriarchal framework of gender and power for future development in the study. The study posit that OTT platforms have taken a step towards bringing equality among and within genders through their representation to make a difference and build acceptance in society for heterogeneity within masculinity.
\end{abstract}

Keywords: Identity, Representation, Gender, Masculinity, OTT Content, Content, New-age media

\section{INTRODUCTION}

Over the years, the concept of masculinity has been understood in the context where men display personality traits like aggression, domination, and control over other genders or appear to be well-built, physically strong, and robust. However, the field of research on masculinities has developed, and the attention is now drawn towards the social construction of masculinity. Masculinity is constructed by society through socialising agents, as they mould and shape accepted and normal gender behaviour in society. It is a changeable social negotiation product developed through social interactions, maintained by gender performativity, carried out unconsciously (Butler, 1990).

The hooks of patriarchy are so deep-rooted that it suppresses women and men who do not fit into the mainstream masculinity framework (Dasgupta and Gokulsing, 2013). In media, both men and women are represented as two polarised characters with clear demarcation of what it is to be a man and be a woman (Beynon, 2002).

Moreover, men in media are painted with the same brush and are forced to fit into the traditional masculinity narrative. Significantly, cultural products like mythology, films, and television have given way to the concept of 'hegemonic masculinity,' which creates a common-sense in society that normalises gender inequalities (Connell, 1995) and produces a one-tone representation of men. These unrealistic images of men make aggression, dominance, homophobia, and heterosexuality normal (Donaldson, 1993). This has led to misguided masculinity, which creates gender politics within masculinity and categorises men into various types hegemony, subordination, complicity, and marginalisation (Connell, 1995, p. 81). Traditional masculinity of this type fails to acknowledge that men cannot be categorised as a homogeneous group. There are different 
types of masculinity that "do not sit side by side" (Connell, 2000, p. 10).

Nevertheless, the wave of representation is changing as the images of masculinity portrayed in media, particularly in Indian content on OTT platforms, are blurring. There has been a shift from the single-layered, unrelatable portrayal of men to men who are supportive, non-macho, are comfortable with their masculinity, and are not threatened by strong women around them, giving hope for better construction of social reality with the entry of such contents.

The existing research and literature on critical men's studies mostly generate images of men as a unitary category: stereotyped based on their physical strength, profession, and control that depicted traditionally held notions of masculinity through cultural products. To fill in this research gap, this paper proposes a revised study of men and masculinity that challenges the patriarchal framework of gender and power that gives way for more varied representation for future development in the field of study.

This paper aims to examine the construction and reconstruction of the changing images of masculinity in the Indian OTT content in contrast to what the mainstream cultural products portray. The objectives of this research study are to examine the changing paradigm shift in the definition and understanding of the concept of masculinity, as well as to analyse the male lead characters and their positioning in India's selected OTT platforms, which does not compartmentalise men's attributes into the existing patriarchal male image.

\subsection{Men and masculinities}

Traditionally, the concept of masculinity is a demonstration of physiological maleness. However, to date, no one thing defines masculinity (Connell, 1995). The narrative of "masculinities without men" (Halberstam, 1998) and heterosexual effeminacy does not exist, and if it does, it is recognised to be associated with gay (Hatfield, 2010). Some stereotypical attributes associated with 'real men' are that they are aggressive, not emotional, dominating, hard-hearted, superior to women, decision-maker, and competitive (Oakley, 1981).
Connell (1987) conceptualises a refined understanding of masculinity with "hegemonic masculinity", which perpetuates gender inequality, not only between men and other genders but also within men. Hegemonic masculinity leads to the creation of a hierarchy of masculinities and idealised form of men (Connell, 1995), which may not correspond to actual men's lives. Nevertheless, men aspire to become like this minority of men who depict hegemonic masculinity (Connell and Messerschmidt, 2005, p. 832) as it is perceived as a higher sense of being a man. Men belonging to the hegemonic masculinity category are always expected to be above society, "breaking whatever or whoever crosses their path" (Faludi, 2000, p. 10). This definition of masculinity has placed men in a state of disadvantage, encircled by three "enemies" - loneliness, compulsive competition, and emotional hesitancy throughout their life (Biddulph, 1995, p. 4). Men who are considered 'soft' are looked down upon in the culture due to which they suffer (Bordo, 2000, p. 55), resulting in anxiety and loneliness (Kimmel, 1996).

\subsection{The 'real' men in Indian mythology, Hindi movies, and television}

Mass media is one of the crucial agencies that exerts influence in the process of perceptioncreating in human beings. It plays a vital part in shaping and re-shaping culture by selecting and projecting a particular way of life as reality, or instead as the only reality. Hence, it is referred to as 'consciousness industries' for it manufactures realities and consent in society (Enzensberger, 1974).

In the Indian context, the concept of masculinity has been reinforced by mythology, movies, and television, which has far-reaching effects on people's psyche. Indian mythology has a diversified representation of gender, which could be observed in various texts. Instances of such representations could be seen in Siva's Ardhanarisvara, divided vertically between half man and half woman figure. In Arjuna, when he spent his exiles with the Pandavas and dressed up as a woman (Nanda, 1993, p. 375). Another example could be seen in Krishna's son, Samba when he gives birth to an iron pestle and mortar when questioned about his feminine attire and pregnancy (Chattopadhyaya, 2008, p. 165-166). 
On the other hand, Bollywood films paint their characters in black and white for the sake of maintaining their viewership, giving little to no scope to the viewers to go beyond what is portrayed (Nandy, 1981, p. 91). Hindi films have a particular prototype for their male lead, starting from the 'angry young man' image of Amitabh Bachchan to the 'manly' identity of Shahrukh Khan, Ajay Devgn, and Sunny Deol in the 90s. Hypermasculinity was buttressed in movies featuring Salman Khan and John Abraham, creating an association of masculinity with gym-toned bodies (Dasgupta and Golkulsing, 2013, p. 14). The 'macho' image of these actors was associated with their rough and tough bodies, who were also authoritarian, rugged, and rebellious (Gabriel, 2010). The year 2000 saw a rise in the "eroticisation of the male body" (Kavi, 2000, p. 308) with Hrithik Roshan's 'Kaho naa... Pyar Hai' (2000) and Ranbir Kapoor's 'Sawariyan' (2007) grabbed the female viewers' attention.

Parallelly, Hindi television has manufactured men's image as practically the breadwinner of the family which could be observed in series like Tu Tu Main Main (1994-2000), Kyunki Saas Bhi Kabhi Bahu Thi (2000-2008), Kahani Ghar Ghar Ki (2000-2008), Sasural Simar Ka (2011-2018), Balika Vadhu (2008-2016), etc. These male characters are continually witnessed validating their female counterparts' existence aand are presented as ideal sons, brothers, or husbands who cut off women who might threaten their power equation (Dasgupta and Golkulsing, 2013, p. 15). Hence, depicting the image of men as the head, decision-maker, and source of power in society.

\subsection{OTT platform: A silver lining?}

With a sharp rise of $30.7 \%$ Compound annual growth rate or CAGR from 2019 to 2024 (Pricewater House Coopers, 2020), the rage of over-the-top (OTT) platforms in India has increased exponentially. The top players like Netflix, Amazon Prime Video, Disney+ Hotstar, Hulu, Zee5, Voot, and TVF Play have also witnessed a growth in their subscription as the OTT market penetrates rural sectors other demographic segments.

These OTT platforms, through their content, are formulating the image of 'new men' who are expressive emotionally and gives importance to inter-personal relationships
(Jeffords, 1993, p. 136). These characters break away from hegemonic masculinities, which are generally portrayed in mainstream films or television products. Such portrayals would activate changes in the widely held commonsense in society about masculinity, for when these hegemonic masculinities accommodate femininity and undergo change frequently, it leads to the formation of newer forms of masculinities that are not so hegemonic to preserve their hegemony (MacKinnon, 2003, p. 73). Such changes would give rise to the acceptance of the image of new, normal, and relatable men.

\section{REVIEW OF LITERATURE:}

The concept of 'masculinity' has been defined and redefined physiologically, socially, and psychologically over the years, which outlines what constitutes a man and what he is like. However, it is imperative to understand 'masculinity' as a concept, developed socially, for society has injected these identities through the socialisation process that shapes individuals' experiences. This literature review examines the construction of 'masculinity' and different dimensions in which it has been represented in the Indian cultural products.

\section{Social construction of masculinity:}

Peter Berger and Thomas Luckmann argue that when a pattern of human behavior is repeated continuously, it results in forming a new reality (Berger and Luckmann, 1967), which they term as the social construction of reality. According to them, the constant reception or performance of a particular belief, idea, or image, might change or alter ideas and beliefs held by the society. Judith Butler asserts that one's identities are constructed by the process of performance, which is unconscious (Butler, 1990). These performances reinforce gender roles, emphasising that gender is constructed through self and social interactions. Hence, masculinity cannot just be understood from the biological perspective. Instead, society constructs these identities, along with developing a hierarchical structure not only between but also within genders. The socialisation agents like school, family, or media inject patterns of gender behaviour that the men pick up over time through feedback and observation (Bandura, 1977). Hegemonic masculinity legitimises the position of a few men while subjugating the majority. Connell 
\& Messerschmidt emphasises that 'hegemonic masculinity' romanticises the "most honoured way of being a man" among the majority, which has no relation to the lives of actual men (Connell \& Messerschmidt, 2005, p. 832). Men are ideologically dominated by masculinity through everyday activities, which is why masculinity is not 'natural' (Itulua-Abumere, 2013, p. 45) and must be understood as an identity that is socially and culturally constructed.

\section{Manufacturing and commodifying masculinity:}

Max Horkheimer and Theodor Adorno explain how due to various factors, media inclines to provide to the consumers' cultural products as a commodity that buttresses the dominant class's ideology (Horkheimer and Adorno, 1972, p. 13). Cultural products like mythology, cinema, and television have been furthering and manufacturing the image of masculinity through their content. Moti Gokulsing \& Wimal Dissanayake points out that cinema is continually building the notion of 'hyper-masculinity' through popular culture to cater to consumerism as the cinema halls are mostly taken by young men (Derné \& Jadwin, 2000).

Movies glorify the male lead's dominance, display aggression, and associates love with violence (Derné \& Jadwin, 2000, p. 243-269), which affects the moviegoers' psyche and shapes the ideal masculine image. The unrealistic, larger than life image of the male lead is portrayed onscreen with machoism, day-saver, and 'appropriately emotional' traits (Goswami, 2016).

In contrast, Sikata Banerjee coins the term 'masculine Hinduism' and states that the image of masculinity is usually equivalent to that of a warrior or soldier with enormous physical strength and high moral values (Banerjee, 2003, p. 168). Gokulsing \& Dissanayake points out that Indian television shows have projected masculinity linearly, reinforcing ideal men's idea, especially concerning women (Gokulsing \& Dissanayake, 2013, p. 15).

\section{OTT platforms in India and new-age men:}

The pricing model, availability of content, proliferation of the internet, and smartphones are key factors contributing to the increase in
OTT platforms' growth (Sujata et al., 2015, p. 48). Tripti Kumari points out that there has been little to no change in television content from the past two decades, making the content on OTT more enticing to the viewers due to its sense of freshness and originality (Kumari, 2020, p. 73).

Eve Shapiro asserts that gendered relations and technology change with time. The effect of the changing gendered relations is visible in technological systems, which formulates new attitudes driven by people themselves (Shapiro, 2015). These changes are likely to break the digital platform content's stereotypical media images (Singh et al., 2020, p. 4). Victor J. Seidler asserts that masculinity is "no longer be expected to be one thing" and allows diversity (Seidler, 1989); leading to the formation of new-age men who do not align with the framework of traditional masculinity. New age men can be associated with a type of masculinity called New Alternative Masculinities (NAM), which stands against violence and sexism, are confident, and base their relationship on love and equality (Ramon et al., 2013, p. 103). The masculinity of this nature stands in sharp contrast with traditional dominant and oppressed traditional masculinities.

The literature studied presents masculinity, cultural products, and over-the-top (OTT) platforms in various contexts. This paper will primarily deal with the changing representation of masculinity, focusing on images portrayed in Indian content on OTT platforms, in order to prove the hypothesis 'Indian Content on OTT platforms is blurring the one-tone representation of masculinity'.

\section{RESEARCH METHODOLOGY}

This paper examines the portrayal of lead male characters from three Indian content on OTT platforms, selected with the purposive sampling method.

\subsection{Research Design}

The study substantiates by the method of discourse analysis, which is selected to examine the meaning embedded in the characters' attitude and their positioning within a social setting (Walliman, 2011). The paper analyses three OTT content - 'Little Things' - Season 1 \& 2 on Netflix, 'Made in Heaven' on Amazon Prime Video, and 'Yeh 
Meri Family' on TVF Play, along with six variables - display of aggression, expression of emotion, domination and control, attitude towards love, work and responsibility, and tolerance to other genders.

\subsection{Variables}

A coding sheet is used to examine selected OTT platform content to analyse them along with six variables: Firstly, display of aggression - Scenes in the content where the male character demonstrates physical or verbal anger to harm or hurt other characters. Secondly, expression of emotions - Scenes in the content where the male character indicates that he lacks emotional intelligence, suppresses his feelings and finds it challenging to empathise with other characters' emotions. Thirdly, domination and control - Scenes in the content where the male character is observed to be the ultimate decider of other people's fate and soft controlling other characters, considering them to be inferior in one way or another. Fourthly, attitude towards love - Scenes in the content where the male character is continually stressed about saving or protecting their loved ones. They feel that other characters are incapable of defending themselves. Fifthly, work and responsibility - Scenes in the content where the male character exhibits the traits of a superhuman that the world revolves around them and that it is their responsibility as a man to save the day. Lastly, tolerance to other genders - Scenes in the content where the male character is homophobic or observed maltreating women.

\section{Data findings and discussion}

\section{Little Things - Season 1 \& 2 (2016, 2018):}

Dice Media's production 'Little Things' on Netflix follows a young couple in a live-in relationship. Kavya Kulkarni is a dreamer and believes in chasing her dreams. She is a successful professional who works hard to move up the corporate ladder. On the contrary, the boy, Dhruv Vats, believes in enjoying the existing realities and is not innately ambitious. He seeks small joys of life, staying at home to watch a football game, cooking food, and travelling long distances to get his favourite dish. This series unravels the organic relationship between the couple in a modern setting.
This study critically examines the male lead character - Dhruv, along six variables, developed to analyse the series.

Firstly, display of aggression - Dhruv, the male protagonist, is a rational person who does not let his emotions sway away when faced with difficult situations. There are sequences of conflict between Dhruv and his old school friend, who is from a more conservative mindset. Dhruv lets his girlfriend Kavya pay for the meal, to which his friend reacts and calls him shameless. Throughout this whole sequence, Dhruv tries to make his friend understand that times have changed while keeping his aggression at bay. In Season 2, Kavya goes to Goa and meets Raunaak, who is considered conventionally attractive, unlike Dhruv. When Kavya tells Dhruv about Raunaak, he does not get upset or takes it to his ego. Instead, he keeps his calm and expresses to Kavya that there will always be someone better out there and what they should focus on is to perfect their ordinary.

Secondly, expression of emotions - Dhruv is a soft-hearted character who is very different from the conventionally attractive, rugged hero persona. He has no calms about getting up from the dining table and getting a glass of water for his girlfriend. There is a sequence where he watches an animated film 'Inside out' and later confesses that he was avoiding watching the movie, as he knew he would cry - a humble confession of vulnerability.

Thirdly, domination and control - Dhruv do not give the impression of a dominating or controlling person. He goes to a parlour with his girlfriend and waits there patiently while she gets a hair spa done while compromising the live football match of his favourite teams Chelsea and Liverpool, in the comfort of his home. He tends to go along with Kavya's plans, changing his desire to make a Thai curry to ordering a pizza instead. He draws happiness from her and their relationship, considering Kavya's plan of a "perfect Sunday" as their perfect Sunday. She insists on going to her friend's home, while Dhruv wants to watch Game of Thrones. They end up agreeing to go to the party that Dhruv is not very keen on going to. This becomes a trend throughout the season, where Kavya makes all the choices, and Dhruv follows. 
Fourthly, attitude towards love - Dhruv values relationships and does not hold himself back to express his affection and care for Kavya. In one of the sequences, Dhruv forgets to iron Kavya's shirt, which she had to wear to work, and upsets her. Later, he sends Biryani to Kavya's office to apologise. When Kavya comes back home after a long day, he offers to warm up pasta for her and asks her if she is carrying a 'Nutribar' when she leaves for work the next day. There is no ordering around taking place in the house but just good balancing. With Kavya feeling unwell, they cancel weekend plans and decide to stay at home. Dhruv books a home beauty service for Kavya, and while she gets it done, he makes food for her. He even decorates the food tray with a hibiscus flower.

Fifthly, work and responsibility - Dhruv is confused about decisions related to his career. He quits his Ph.D. and later his job because he was not enjoying his work. Since Dhruv is out of work and broke at times, when his friend from school meets him, Kavya pays for the dinner. This action does not go down well with his friend, and he ends up calling him shameless. However, Dhruv sees no harm in it.

In an episode when Dhruv loses his job and Kavya is promoted to a managerial position, he does not bash himself down for not taking up responsibility as a man. Later in the series, Kavya convinces him to allow her to help him with the loan, to which he is reluctant at first but later agrees. He takes things lightly and does not push himself to stress, bringing everything to his ego. Sixthly, tolerance to other genders - Dhruv takes Kavya's mom around, makes her feel comfortable, and even teaches her how to use a smartphone. Throughout the series, Dhruv is kind and respectful around people of other genders around him.

The study reveals that Dhruv is a composed individual who tries to find a logical and reasonable explanation of everything he comes across. He is not hot-headed and manages the situation with the utmost thoughtfulness. He expresses his emotions in the most humane way and puts Kavya as his priority to convey his love for her. In most situations, he takes a back-seat because that is what he is as a person and not someone controlling. Dhruv, career-wise, is confused but not lost. He does not feel that as a man, it is his responsibility to run the house. He does not believe in gendering roles. Nor does he get obstructive when he loses his job while his girlfriend gets promoted. He is confident and not a shallow person. Hence, Dhruv gives the impression of a modern man who breaks away from the definition of traditional masculinity portrayed.

\section{Made in Heaven (2019):}

Amazon Prime Video series 'Made in Heaven' (2019) is a story that revolves around two friends cum colleagues - Tara Khanna (Sobhita Dhulipala) and Karan Mehra (Arjun Mathur). They jointly own a wedding management company, 'Made in Heaven,' located in Delhi, and targets the upper crust of the society for business. Created by Zoya Akhtar and Reema Kagti, this show explores the intricacies of relationships with friends, families, and self and exposes the so-called liberal mindset of the bourgeois class and their societal hypocrisy. The series portrays glimpses of the brutalities of social dilemmas like dowry, homophobia, and classism.

This study critically examines the male lead character - Karan Mehra, along with six variables developed to analyse the series.

Firstly, display of aggression - The character of Karan Mehra comes across as a supportive, reasonable, and understanding individual. $\mathrm{He}$ does not act out of impulsiveness and shows signs of unnecessary aggression. In a scene, Tara Khanna, Karan's business partner, and friend is disturbed due to turmoil in her relationship and makes a personal attack on Karan regarding his habit of borrowing money and investing in the wrong places. However, Karan understands that Tara uttered the statements due to stress. He does not get aggressive or defensive. Instead, he gives Tara the benefit of the doubt. In another scene, where Karan's landlord, Ramesh Gupta, and his wife barges into Karan's apartment and demands him to leave, Karan takes an uncompromising stand for himself. Instead of displaying aggression, he argues that legally he is a tenant of the apartment and cannot be forced to leave immediately. He deals tactfully with the situation, maintaining respect and dignity. 
Secondly, expression of emotions - Karan's emotional graph changes in the series. During his teenage days, Karan found it challenging to be expressive. He found it difficult to express his love for Nawab, and was afraid to accept himself as a homosexual, or stand up to his friends or mother for Nawab. However, with time he became expressive. In a scene when Karan gets bail from the jail under Section 377, he is seen breaking down inconsolably after his father shows him support when he needed the most. He does not hold himself back when Tara hugs and consoles him. Karan shows courage and vulnerability when he apologises to Nawab for making fun of him in front of their friends and letting him down. After his meet with Nawab, he realises that he lost the only one he ever loved, which breaks his heart, and yet again, Karan cries uncontrollably in the scene.

Thirdly, domination and control - In the series, Karan is street smart, who handles the situation tactfully whenever required, an example of which could be observed when he cancels the media conference due to the Sarfaraz mishap when Simranpreet goes through an emotional dilemma. Karan takes over both situations but does not come across as controlling or superior. Instead, he appears as a leader who wants to fix the situation without making others feel inferior.

Fourthly, attitude towards love - Nawab is the only person Karan truly loves. Once he made fun of him in front of their friends for loving him, which still haunts Karan. Years later, when he meets Nawab, he is not afraid to express his love and affection. He also expresses his love towards his long-term elderly employee, Khalil Ansari, by clearing the loan of two lakhs rupees, taken by Khalil to execute his daughter's marriage.

Fifthly, work and responsibility - Karan appears as a person who takes a stand for the right. Karan also looks down upon the man from Ludhiana who arranges a beauty contest to choose a bride and, in another scene, is witnessed coming in full support of Pooja, a henna artist, who was molested at the wedding. He gets upset with Pooja when she accepts the money offered to her by Devyani instead of fighting for justice. However, he takes a step ahead in getting justice delivered to Pooja by releasing the news to the press via his journalist friend. Later in the series, Karan admits that he has been living his life as a coward but is now ready to take responsibility and accept who he is and indulges in activism.

Sixthly, tolerance to other genders - Karan initially is ashamed of his sexual orientation due to negative reinforcements he underwent as a teenager. When his friends find out that he received a note saying "I love you" from Nawab, he denies having any association with Nawab as he felt humiliated being labelled gay. However, growing up, he becomes more accepting of himself and others. When he finds out that his property owner, Ramesh Gupta is gay and is prey of misguided masculinity, he sympathises with him and decides not to file a case against him. Later, Karan files Public interest litigation (PIL) against Section 377 to support himself and the rest of the LGBTQ community and indulges in activism.

The study reveals that Karan Mehra is a character that rejected the traditional masculinity framework. He is not aggressive and deals with situations tactfully and with dignity. He did not shy away from expressing his emotions, is respectful, and empathised with people from other genders. Karan came across as a leader who is friendly and not dominating. He is a person with a heart filled with affection for the people around him who dares to fix his mistakes and stand up for the right. Karan breaks the monotony and stereotypical portrayal of masculinity.

\section{Yeh Meri Family (2018):}

TVF's series 'Yeh Meri Family' (2018) is a sweet, nostalgic story set in 1998, Jaipur, about a family of five. The story is narrated over a summer holiday by a thirteen-year-old boy, Harshu Gupta (Vishesh Bansal), the middle child in his family. The show explores the dayto-day trials of a teenager in the 90's backdrop and how he deals and learns through it. The series also reflects relationships in their rawest form, be it with or between parents, siblings, crushes, or friends.

This study critically examines the male lead character - Devendra Gupta (Harshu's father), along with six variables developed to analyse the series. 
Firstly, display of aggression - The character of Devendra Gupta, the father, comes across as a straightforward and understanding person who is mostly calm and collected. For instance, in a scene where Harshu, the middle child, scores less in his Hindi exam, instead of getting irritated, he shows faith in his son that he would do better next time. In another scene, when Harshu's mother finds out about the pornographic magazine, she hits and scolds him. Devendra assesses the situation maturely and tells his wife that it is a normal teenage behaviour. However, there is one instance where Devendra loses his temper after a spat with his wife in the series. Out of frustration, he slaps his daughter, Chitti. Nevertheless, later in the series, he apologises to her for his unreasonable behaviour.

Secondly, expression of emotions - Devendra shows emotions implicitly throughout the series. He is not expressive or vocal about his emotions but demonstrates them through actions. When Harshu asks him for 100 rupees to go out with his friends on his birthday, he understands that 100 rupees might be too less and offers more. Moreover, he tells him that the most important thing is for him to go and return safely from the restaurant. Similarly, when his elder son Dabbu leaves for a coaching institute, he cross-checks if he has the ticket and selection letter. This shows how caring a father Devendra is.

Thirdly, domination and control - Devendra is the breadwinner of the family but is not dominating or controlling. He does not control his sons; instead, he supports them. At work, he logically and reasonably makes his clients understand their policy instead of soft controlling them.

Devendra encourages his elder son, Dabbu, to participate in the cricket tournament despite his coaching entrance exam. He does not act dominating that he must only study. According to him, sports build character, and studies should not always be one's priority. Fourthly, attitude towards love - Devendra has his way of love for his children and wife. He does not feel embarrassed to exhibit his love or affection, but neither does he explicitly say that he loves them. Instead, he shows it through action. For instance, he tells Harshu that it is essential that he goes and returns safely after meeting his friends, and when he cross-checks with Dabbu if he has collected his tickets and selection letter.

In another scene, he cheers and claps for his Dabbu during his cricket tournament to encourage and boost his confidence. $\mathrm{He}$ is always the one clicking his family picture and ends up not being a part of it, and works late at night after everyone is asleep so that his family time does not get compromised. Fifthly, work and responsibility - Devendra is a responsible father and husband who does not exhibit superhuman powers, but a father and husband who is relatable and concerned about his family. When Devendra's elder son, Dabbu, leaves for the coaching institute, his mother breaks down. At that point, he feels it is his responsibility as a family member to comfort his wife. He hugs her and explains that it is okay for him to leave to build his career and life. His taking up of responsibility, does not boil down to his masculinity. Sixthly, tolerance to other genders - Devendra, throughout the series, is seen to be respectful towards his wife.

The study reveals that Devendra Gupta is a character that rejects the traditional masculinity framework. He is a simple man who assesses situations mindfully and acts accordingly, showing little to no aggression signs. He has his ways of expressing emotions through his actions, is respectful towards his wife, and maintains dignity even during arguments. He is an encouraging father and worker who does not try to dominate or control. He understands that he is not perfect and tries to figure out his way through fatherhood by learning through his mistakes. In this way, Devendra breaks the monotony and stereotypical portrayal of masculinity.

Hence, it is observed that in the selected OTT content, the male leads have defied the stereotypical traditional notion of masculinity and are seen creating a new, diversified narrative of healthy masculinity. Thus, the study's hypothesis - Indian Content on OTT platforms is blurring the one-tone representation of masculinity is proved through the study.

\section{CONCLUSION}

The concept of masculinity is a social construct, built block by block through socialising agents like school, family, media, 
and other social institutions. These agents collectively create unrealistic expectations for men, labeling aberrations of any kind as not manly enough. However, OTT platforms' entry is seen as the perception-changer as they blur the stereotypical images of masculinity. The experience of content consumption shapes our realities (Berger and Luckmann, 1967). It widens its consumers' mental horizon, making us more accepting while giving way to healthy masculinity that does not adhere to stereotypical roles assigned to men. Some content on these platforms has instrumentally changed the portrayal of their male characters, giving way to more diversified, layered characters to men instead of the same aggressive, controlling, and emotionless. These contents are silver linings as they do not compartmentalise their male characters into the 'traditional' or 'hegemonic' masculinity framework. Instead, the characters on the platforms act as a breath of fresh air as they break away from the usual portrayal of men associated with violence or muscular bodies, who are the saviour of women and hovers over everyone's lives like supermen. These characters come across as regular, relatable people with emotional awareness and compassion, who do not appear to be larger than life, nor do they fit into the patriarchal male image. OTT platforms have taken a step towards bringing equality among and within genders through their representation to make a difference and build acceptance in society for heterogeneity within masculinity.

\section{REFERENCES}

Bandura, A. (1977). Self-efficacy: Toward a unifying theory of behavioral change. Psychological Review, 84(2), 191-215. https:// doi.org/10.1037/0033295x.84.2.191

Banerjee, S. (2003). Gender and nationalism: the masculinization of hinduism and female political participation in india. Women's Studies International Forum, 26(2), 167-179. https://doi.org/10. 1016/s0277-5395(03)00019-0

Berger, P. L., \& Luckmann, T. (1967). The Social Construction of Reality: A Treatise in the Sociology of Knowledge. Anchor. https://www.perflensburg. se/Berger\%20social-construction-ofreality.pdf
Beynon, J. (2002). Masculinities and Culture (Management in Education Series) (1st ed.). Open University Press.

Biagi, S. (2012). Media Impact: An Introduction to Mass Media, 2013 Update (Wadsworth Series in Mass Communication and Journalism) 10th edition by Biagi, Shirley (2012) Paperback (10th ed.). Cengage Learning.

Biddulph, S. (1995). MANHOOD : A Book About Setting Men Free. Finch Publishing.

Bordo, S. (2000). The Male Body. Farrar, Straus and Giroux.

Butler, J. (1990). Gender Trouble: Feminism and the Subversion of Identity (Routledge Classics) 1st (first) edition (1st Edition). Routledge.

Chattopadhyay, B. (2008). Krishna Charitra. V \& S Books.

Connell, R. W. (1987). Gender and Power: Society, the Person, and Sexual Politics (1st ed.). Stanford University Press. https://doi.org/10.1177/0270467688008 00490

Connell, R. W. (1990). The state, gender, and sexual politics. Theory and Society, 19(5), 507-544. https://doi.org/10. $1007 /$ bf00147025

Connell, R. W. (1995). Masculinities. University of California Press.

Connell, R. W. (2000). The Men and The Boys (1st ed.). University of California Press.

Connell, R. W., \& Messerschmidt, J. W. (2005). Hegemonic Masculinity. Gender \& Society, 19(6), 829-859. https://doi. org/10.1177/0891243205278639

Dasgupta, R., \& Gokulsing, M. (2013). Introduction: Perceptions of Masculinity and Challenges to the Indian Male. In Masculinity and Its Challenges in India: Essays on Changing Perceptions (pp. 526). McFarland.

Derné, S., \& Jadwin, L. (2000). Male Hindi filmgoers' gaze: An ethnographic interpretation. Contributions to Indian Sociology, 34(2), 243-269. https://doi. org/10.1177/006996670003400204 
Donaldson, M. (1993). What is hegemonic masculinity? Theory and Society, 22(5), 643-657. https://doi.org/10.1007/ bf00993540

Enzensberger, H. M. (1974). The Consciousness Industry: On Literature, Politics and the Media (A Continuum Book) (First American Edition). Seabury Press.

Faludi, S. (2000). Stiffed: The Betrayal of the American Man (Reprint ed.). William Morrow Paperbacks.

Future of OTT in India. (2016, April 1). NASSCOM Community | The Official Community of Indian IT Industry. Retrieved November 26, 2020, from https:/ / community.nasscom.in/commu nities/digital-transformation/telecommedia-communities/future-of-ott-inindia.html\#:\%7E:text=Market $\% 20$ size $\% 2$ OUSD $\% 205 \% 20$ bn,bn $\% 20$ in $\% 20$ size $\% 20$ b $\mathrm{y} \% 202023$.

Gabriel, K. (2021). Melodrama and the Nation: Sexual Economies of Bombay Cinema 1970-2000 (2010th ed.). SAB.

Goswami, A. (2016). 'New Bollywood' and the emergence of a 'Production House' culture. South Asian Popular Culture, 14(3), 185-197. https://doi.org/10. 1080/14746689.2017.1294805

Halberstam, J. (1998). Female Masculinity. Duke University Press.

Hatfield, E. F. (2010). "What it Means to Be a Man": Examining Hegemonic Masculinity in Two and a Half Men. Communication, Culture \& Critique, 3(4), 526-548. https://doi.org/10.1111/ j.1753-9137.2010.01084.x

Horkheimer, M., \& Adorno, T. W. (1972). Dialectic of Enlightenment. Amsterdam University Press.

Itulua-Abumere, F. (2013). Understanding Men and Masculinity in Modern Society. Open Journal of Social Science Research, 1(2), 42. https://doi.org/10. 12966/ojssr.05.05.2013

Jeffords, S. (1993). Hard Bodies: Hollywood Masculinity in the Reagan Era (None ed.). Rutgers University Press.
Kavi, A. R. (2000). The Changing Image of the Hero in Hindi Films. Journal of Homosexuality, 39(3-4), 307-312. https://doi.org/10.1300/j082v39n03_15

Kimmel, M. (1996). Manhood in America (1st ed.). The Free Press.

Kumari, T. (2020). A Study on Growth of Over the Top (OTT) Video Services in India. International Journal of Latest Research in Humanities and Social Science (IJLRHSS), 3(9), 68-73. https://www.ijlrhss.com/paper/volum e-3-issue-9/11-HSS-747.pdf

MacKinnon, K. (2003). Representing Men (Arnold Publication) (1st ed.). Bloomsbury Academic.

Nanda, S. (1993). Hijras:: An Alternative Sex and Gender Role in India. In Third Sex, Third Gender: Beyond Sexual Dimorphism in Culture and History (pp. 373-418). Zone Books.

Nandy, A. (1981). The Popular Hindi Film: Ideology and First Principles. India International Centre Quarterly, 8(1), 8996.

Oakley, A. (1981). Subject: Women. Pantheon Books.

Price Waterhouse Coopers. (2020). The Global Entertainment \& Media Outlook 20202024. PwC. Retrieved December 10, 2020, from https://www.pwc.com/ outlook

Ramon, F., Puigvert, L., \& Ríos, O. (2013). The New Alternative Masculinities and the Overcoming of Gender Violence. International and Multidisciplinary Journal of Social Sciences, 2(1), 88-113. http:/ / carei.es/archivos_materiales/ne w\%20alternatives \%20masculinities \%20( 3).pdf

Seidler, V. J. (1989). Rediscovering Masculinity: Reason, Language and Sexuality (1st ed.). Routledge.

Shapiro, E. (2015). Gender Circuits: Bodies and Identities in a Technological Age (Sociology Re-Wired) (2nd ed.). Routledge.

Singh, V. K., Chayko, M., Inamdar, R., \& Floegel, D. (2020). Female librarians and male computer programmers? Gender 
bias in occupational images on digital media platforms. Journal of the Association for Information Science and Technology, 71(11), 1281-1294. https://doi.org/10.1002/asi.24335

Sujata, J., Sohag, S., Tanu, D., Chintan, D., Shubham, P., \& Sumit, G. (2015). Impact of Over the Top (OTT) Services on Telecom Service Providers. Indian Journal of Science and Technology, 8(S4), 145. https://doi.org/10.17485/ ijst/ 2015/v8is4/62238
Van der Watt, S. (2013). Masculine identity and the projection of 'male images' in mass media: towards a pastoral hermeneutics in theory formation. Nederduitse Gereformeerde Teologiese Tydskrif, 53(3-4), 353. https://doi.org/10.5952/53-3-4-274

Walliman, N. (2011). Research Methods: The Basics (1st ed.). Routledge. 